\title{
L'anthracnose du pois. Revue bibliographique et synthèse
}

\author{
C Allard, L Bill *, G Touraud \\ INRA, Station de pathologie végétale, 78026 Versailles Cedex, France
}

(Reçu le 29 septembre 1992; accepté le 5 octobre 1992)

\begin{abstract}
Résumé - Trois Sphaeropsidales apparentées (Ascochyta pisi, Mycosphaerella pinodes, Phoma medicaginis var pinodella) provoquent sur les divers organes du pois des macules nécrotiques et affectent le rendement et la qualité des récoltes. Le diagnostic des trois parasites par simple visualisation de symptômes reste aléatoire en raison de leur similitude pour les trois espèces et de la superposition fréquente de ces dernières sur la même plante-hôte. Cependant, l'observation au champ complétée d'une étude au laboratoire permet de proposer une clef de détermination.

Des trois parasites, $A$ pisi est l'espèce qui attaque le plus fréquemment les semences de pois. Cependant, compte tenu de l'agressivité de chaque champignon, Neergard (1979) considère comme économiquement acceptables des fréquences de contamination de la semence 4 fois plus élevées pour $A$ pisi que pour $M$ pinodes. La majorité des semences envahies par $\boldsymbol{A}$ pisi provient de gousses ne présentant pas de symptômes typiques. L'infection primaire de l'épicotyle n'est généralement pas décelable visuellement. Contrairement à $M$ pinodes et $P$ medicaginis, ce parasite ne produit ni microsclérotes, ni chlamydospores. Les chlamydospores de $P$ medicaginis sont les mieux représentées dans le sol; leur agressivité vis-à-vis du système racinaire (footrot) augmente avec la répétition des cultures de la plante-hôte. Dix pour cent des infections primaires par $M$ pinodes s'extériorisent entre la $4^{\mathrm{e}}$ et la $5^{\mathrm{e}}$ semaine de culture au niveau des écailles. Dans la majorité des cas, l'infection se manifeste à partir de la $6^{6}$ semaine au niveau de l'épicotyle. À un faible taux de contamination des semences est associée une agressivité élevée vis-à-vis des entrenœuds de la plantule. La propagation liée à l'existence de plusieurs générations de pycnospores r'étant assurée que par les éclaboussements consécutifs aux pluies, elle reste de faible portée. Néanmoins, les ascospores transportées par voie aérienne confèrent à la phase sexuée homothallique de $M$ pinodes des potentialités accrues de transmission et de dissémination secondaire. Heath et Wood (1969) décrivent la nécrogenèse chez $M$ pinodes. Les macules limitées (nécroses brunes à croissance très lente et à parois cellulaires épaissies) sont presque stériles. En revanche, les lésions évolutives, plus claires, à croissance active, et parois cellulaires dégradées, portent de nombreuses pycnides. La fréquence des lésions évolutives augmente avec la quantité d'inoculum déposée, l'âge et la turgescence des organes. Pour ces auteurs, la résistance des parois à la macération ne serait pas la cause principale de l'arrêt du développement des macules limitées. Aussi celle-ci ne doit-elle pas être recherchée dans l'inhibition des enzymes de macération par les polyphénols, mais plutôt dans la synthèse de novo d'un ou plusieurs inhibiteurs de la croissance fongique. Les conditions de développement des lésions évolutives sont, quant à elles, en rapport avec la capacité de $M$ pinodes à inactiver par voie enzymatique (déméthylation adaptative) une phytoalexine du pois, la pisatine. La variabilité de la virulence chez $A$ pisi et $M$ pinodes a été décrite pour deux ensembles distincts de lignées de pois. Deux lignées caractérisées par une bonne résistance de l'épicotyle à un échantillonnage d'isolats et de pathotypes de $M$ pinodes, pourraient constituer des sources de résistance utilisables dans un programme d'amélioration. La résistance à A pisi est recherchée par l'utilisation d'une lignée sélectionnée vis-à-vis des pathotypes les plus répandus en Europe. Toutefois, une telle démarche ne garantit pas une résistance vis-à-vis de la totalité des pathotypes européens. Actuellement, la protection contre ces maladies fait surtout appel au traitement des semences. Toutefois la stratégie de lutte repose sur la création de cultivars de pois résistants et la production de semences saines.
\end{abstract}

Pisum sativum / Mycosphaerella pinodes / Ascochyta pisi / Phoma medicaginis / symptomatologie (champignons maculicoles) / cycle biologique / phytoalexine / diagnostic / résistance / pathotypes / amélioration du pois

Summary - Ascochyta spp: review of the literature and synthesis. Three related Sphaeropsidales (Ascochyta pisi, Ascochyta pinodes (teleomorph Mycosphaerella pinodes, Phoma medicaginis var pinodella) induce spot-like necrosis on pea organs and cause yield and seed quality losses. Diagnosis of the 3 agents based on symptoms remains 
partly speculative: symptoms are fairly similar in the 3 species and may be mixed on the same host plant. However, a diagnostic key is provided by field observation associated with laboratory investigation. Among the 3 seed-borne pathogens, A pisi is the most frequently observed in the seeds. Nevertheless, because of the agressiveness of each fungus, Neegard (1979) estimates that the acceptable disease tolerance level for A pisi is 4-fold that for $M$ pinodes. The majority of seeds contaminated by A pisi are attacked without typical symptoms on pods. Primary epicotyl infections are not generally visually detectable. In contrast with $\mathrm{M}$ pinodes and $\mathrm{P}$ medicaginis, A pisi produces neither microsclerotia nor chlamydospores. The chlamydospores of $\mathrm{P}$ medicaginis are most frequently isolated from the soil; their agressiveness towards roots (footrot) increases with continuous pea cropping. Ten percent of primary $\mathrm{M}$ pinodes infections appear during the 4th and 5th week on embryonary bracts. The bulk of infections are observed on the epicotyl after the 6th week. Weak contamination is able to provoke a high level of agressivity towards the plumule. Dispersal of several generations of pycnospores in the field occurs only through rainfall (splashing) and remains limited. Nevertheless, wind-borne ascospores provided from the homothallic phase of $\mathrm{M}$ pinodes provide higher potentialities for transmission and secondary spread of the disease. Heath and Wood (1969) showed the formation of leafspots induced by $\mathrm{M}$ pinodes. They discriminated limited necroses from spreading lesions. Limited necroses are brown, have a slow growth rate and thickened cell walls. They are almost sterile. Spreading lesions are light green with degraded walls and bear numerous pycnidia. Their frequency increases with inoculum concentration, spore deposit, ageing and turgidity of organs. According to these authors, the major factor in hindering the development of limited lesions is not the resistance of plant cell wall to maceration. This suggests the role of de novo biosynthesis of one (or more) growth inhibitor(s) rather than the inhibition of macerating enzymes by polyphenols. The development of spreading lesions is associated with $\mathrm{M}$ pinodes' ability to inactivate the phytoalexin in pea (pisatin) by enzymes (inducible demethylation). The variability in virulence of $\mathrm{A}$ pisi and $\mathrm{M}$ pinodes has been recently described for 2 separate sets of pea lines. Two strains, showing a good resistance of the epicotyl to isolates and pathotypes of $M$ pinodes, may become useful sources of resistance. A pisi resistance exists in a line selected towards the more frequently isolated pathotypes in Europe. Nevertheless, this resistance does not ensure incompatibility towards all European pathotypes. Currently, the methods of control consist of fungicide treatment of seeds. A long-term strategy for Ascochyta disease must be based on the breeding for resistant cultivars and the production of disease-free seeds.

Pisum sativum / Mycosphaerella pinodes / Ascochyta pisi / Phoma medicaginis / Ascochyta disease complex / symptomatology (leaf spots, fungi) disease cycles / phytoalexin / diagnosis / resistance / pathotypes / pea breeding

\section{INTRODUCTION}

Les organes aériens du pois (Pisum sativum $\mathrm{L}$ ) sont fréquemment maculés de nécroses brunes résultant de l'action d'un ou plusieurs champignons, parmi les espèces suivantes : 1) Ascophyta pisi Lib; 2) Mycosphaerella pinodes (Berk et Blox) Vestergr = Didymella pinodes (Berk et Blox) Petrak; stade asexué : Ascochyta pinodes (Berk et Blox) Jones; 3) Phoma medicaginis var pinodella (Jones) Boerema $=A$ pinodella Jones.

II est commode de qualifier d'anthracnoses l'ensemble de ces maladies apparentées (Viennot-Bourgin, 1949; Chup et Sherf, 1960). Cependant, les auteurs anglo-saxons réservent ce terme à la maladie causée par Colletotrichum pisi Pat-Hare et Walker (1944), puis Walker (1952) considèrent trois Ascochyta diseases ou Ascochyta blights: Mycosphaerella blight, Pinodella blight, Pisi blight. Pisi blight équivaut à Ascochyta blight and Pod Spot. Pour sa part, Wallen (1965) envisage un Ascochyta Complex on Peas.

L'attaque des feuilles d'une plantule de pois par $M$ pinodes ou par $P$ medicaginis est le plus souvent précédée par celle de la région de l'axe proche des cotylédons (Gilchrist, 1926; Hare et Walker, 1944). Par ailleurs, un syndrome de nécrose du pied et des racines (foot and root rot) est souvent observé. II résulte de l'action combinée de champignons telluriques. Parmi eux, et selon les régions de culture, FR Jones et Linford (1925), Davis et Shehata (1985), Bodker (1989), Biddle (1983), Didelot et al (1992) reconnaissent avec une fréquence élevée Fusarium solani (Mart) Appel et $\mathrm{Wr} f \mathrm{sp}$ pisi (FR Jones) Snyd et Hans et à moindre degré $P$ medicaginis var pinodella (LK Jones) Boerema et également $M$ pinodes.

En France, le retour des cultures sur les mêmes parcelles, lié à l'extension des surfaces consacrées aux espèces protéagineuses (663 000 ha de pois de printemps et 29000 ha de pois d'hiver, pour l'année 1990), s'accompagne d'un accroissement de la fréquence du syndrome de nécrose du pied et des racines. Deux essais menés par l'ITCF ont montré que ce syndrome pouvait provoquer une perte de rendement de $30 \%$.

De son côté, par l'utilisation d'infections dirigées, Wallen (1965) estime les pertes de rende- 
ment dues au développement de $M$ pinodes, $P$ medicaginis et $A$ pisi à respectivement 45,25 et $11 \%$. Ce résultat suggère que chaque parasite est doué de potentialités spécifiques.

Suivant les circonstances, $M$ pinodes peut se révéler très proche d'A pisi ou de $P$ medicaginis. La documentation présentée ici se propose de faire le point sur les critères permettant d'éviter des confusions aussi bien entre les trois champignons cultivés in vitro qu'entre les symptômes que chacun provoque habituellement. Elle s'appuie plus particulièrement sur les travaux de Heath et Wood (1969; 1971 a,b) grâce auxquels nous disposons d'une interprétation physiologique, encore trop méconnue, de la genèse des lésions provoquées par $A$ pisi et $M$ pinodes. Les différences mises en évidence permettent une discrimination des symptômes imputables à chacun des parasites sur les organes aériens de la plante hôte.

Sur le plan pratique, alors qu'un intérêt particulier est accordé au pois quant à sa résistance à $A$ pisi et $M$ pinodes, nous espérons faciliter le travail de sélection en proposant une interprétation correcte des réponses servant de support aux notations; à savoir, les échelles élaborées par Cousin et al (1985), Darby et al (1985) pour $A$ pisi et par Clulow et al $(1991 \mathrm{a}, \mathrm{b})$ pour $M$ pinodes.

\section{LES ANTHRACNOSES : HISTORIQUE ET TAXONOMIE DES TROIS AGENTS RESPONSABLES}

Stone (1912) observe sur pois des attaques par $A$ pisi Lib suivies par l'apparition des périthèces de Sphaeria pinodes Berk et Blox (Berkeley, 1841) Sphaerella pinodes (Berk et Blox) Niessl (Rabenhorst, 1884) et propose pour ce dernier la combinaison nouvelle $M$ pinodes (Berk et Blox) Stone, téléomorphe d'A pisi Lib.

C'est à partir d'une espèce voisine d'A pisi Lib, responsable sur pois de symptômes distincts et décrite comme $A$ pinodes Berk et Blox, que LK Jones (1927, a,b) obtient en culture axénique la forme sexuée $M$ pinodes (Berk et Blox) Stone. Linford et Sprague (1927) reconnaissent deux modalités de symptômes foliaires, associables à deux Ascochyta distincts; une "forme claire» (à pycnides claires) imputable à $A$ pisi Lib et une "forme foncée" (à pycnides foncées), liée à la phase asexuée de $M$ pinodes (Berk et Blox) Stone.
Ces résultats sont confirmés par Wehlburg (1932), Sattar (1933) et Noll (1939) à partir de matériels provenant d'Europe et d'Inde. Selon Sprague (1929), les deux formes de $M$ pinodes, peuvent être isolées in vitro, à partir de nécroses foliaires sur Pisum, Lathyrus tingitanus et Lathyrus odoratus. Toutefois, ce champignon se révèle plus polyphage et peut aussi être observé à la base des tiges d'autres légumineuses (Bouznad, 1989).

Petrak (1924) observe la présence de paraphyses fugaces habituellement associées au genre Didymella. Aussi, Punithalingam et Holliday (1972) admettent-ils la synonymie Didymella pinodes $($ Berk et Blox) Petrak $=M$ pinodes $($ Berk et Blox) Vestergr. Toutefois, cette dernière combinaison reste seule consacrée par l'usage, ce qui justifie son emploi dans cet article.

Le genre Ascochyta Libert est redéfini par Saccardo (1884). $Y$ sont incluses les espèces produisant des conidies, biloculaires, ovoïdes ou blongues, hyalines ou verdâtres et à extrémités arrondies, au sein de pycnides (conidioma) membraneuses, globuleuses ou lenticulaires, munies d'une papille et d'un ostiole. Les conidies formées in vitro par les espèces d'Ascochyta (lectotype $A$ pisi Lib) possèdent parfois 2 ou même 3 cloisons (Buchanan, 1987).

Les feuilles des espèces appartenant au genre Vicia sont attaquées par des Ascochyta que Sprague (1929) assimile à $A$ pisi Lib. Cependant des infections croisées montrent que ces parasites de légumineuses voisines du genre Pisum ne sont pas polyphages (Bouznad, 1989).

Par ailleurs, FR Jones et Linford (1925) signalent sur pois la présence d'un champignon maculicole proche du genre Phoma, que LK Jones (1927b) décrit comme A pinodella.

En 1965, Boerema et al, comparant les champignons responsables du complexe pourriture du pied - macules foliaires sur Medicago sativa L, Trifolium pratense L, Pisum sativum L aboutissent aux conclusions suivantes : 1) Le nom correct du champignon inféodé à $M$ sativa est $P$ medicaginis Malbr et Roum (et non Phoma herbarum West); 2) $T$ pratense et $P$ sativum hébergent un même champignon, bien connu aux Pays-Bas sous la terminologie d'A pinodella Jones adoptée par Wehlburg (1932). Ce parasite peut être considéré comme une variété polymorphe et polyphage de $P$ medicaginis Malbr et Roum. Aucune raison ne justifiant un nouveau taxon, son nom correct est donc $P$ medicaginis var pinodella (Jones) Boerema. 
Quelques figures de conidiogenèse définies par Brewer et Boerema (1965) en microscopie électronique à transmission, confirmeraient que ce parasite n'appartient pas au genre Ascochyta. Cependant, l'interprétation des travaux ultérieurs de Boerema et Bollen (1975) sur la conidiogenèse de type annellidique chez les espèces $A$ pinodes et $A$ fabae n'est pas admise par Punithalingam (1979), Buchanan (1987), Bouznad (1989) qui observent chez A pisi des structures de type phialide.

La terminologie recommandée par Boerema met l'accent sur les liens entre deux champignons parasites de grandes cultures. N'en suggère-t-elle pas trop par rapport à nos connaissances réelles concernant l'adaptation au pois du parasite de la luzerne, dans un système cultural ?

Cependant, il nous est apparu que, même si les critères retenus par Boerema et al paraissent insuffisants pour justifier la distinction entre les genres Ascochyta et Phoma, les similitudes reconnues par divers auteurs à propos de la conidiogenèse chez les parasites du pois n'autorisent pas à les regrouper dans le même supergenre. C'est pourquoi nous considérons que l'une des espèces telluriques induisant sur pois la formation de macules appartient au genre Phoma (Dorenbosch, 1970) favorisé par l'intensification des cultures.

\section{DIAGNOSTIC DES ANTHRACNOSES DU POIS}

\section{Progression des symptômes}

A pisi (Punithalingam et Holliday; 1972; CMI 334) peut attaquer les divers organes aériens juvéniles. La maladie se manifeste par des nécroses non coalescentes, d'abord translucides, puis brun clair en leur centre et entourées par une zone diffuse brun foncé. Sur les pétioles, entre-nœuds et gousses, apparaissent des dépressions allongées bien délimitées, d'un aspect parcheminé. Des pycnides glabres, facilement repérables à leur cirrhe, se groupent au centre des macules.

Des ponctuations rapprochées (criblures) de couleur foncée et sans marge distincte (Dixon, 1988) sont l'indice du début de l'infection par $M$ pinodes (Punithalingam et Holliday, 1972). On observe plus tardivement le développement de halos translucides verts et à auréoles concentriques correspondant à une première génération de pycnides. Après la nécrose des faisceaux libéro-ligneux des pétioles et des nervures, et colonisation totale du limbe flétri, un thalle est à l'origine de pycnides distribuées au hasard, puis de périthèces. Les stries brunes caractéristiques d'une infection de l'épicotyle (footrot) s'étendent vers les écailles où apparaissent les foyers primaires. L'invasion de la tige à partir des pétioles et stipules préalablement colonisés (comme le cheminement inverse) se manifeste par le développement de larges macules brun violacé. La croissance des organes apicaux ainsi que celle des jeunes gousses s'en trouve affectée. L'invasion post-florale des apex n'entraîne pas de brunissement et aboutit à une dernière génération de périthèces.

Chez $P$ medicaginis, l'invasion des entrenœuds inférieurs provoque l'apparition de nécroses violacées. Elle précède habituellement l'attaque des pétioles et des limbes qui est à l'origine de la pycnidogenèse.

\section{Observation des symptômes et des caractéristiques morphologiques du parasite : application au diagnostic}

Le problème le plus fréquent consiste en une infection précoce simultanée de la région des isthmes (connectifs reliant les cotylédons à la base de la tigelle) par $M$ pinodes et $P$ medicaginis. Ceux-ci occasionnant des symptômes très similaires, l'établissement d'une clef dichotomique basée sur l'observation de ces derniers est difficile. Aussi, même en prenant en considération l'âge de la plante et des différents organes susceptibles d'être attaqués, une étude au laboratoire reste-t-elle nécessaire.

Le diagnostic débute par la recherche d'une association entre macules foncées très rapprochées (criblures) à extension limitée et sans marge distincte et lésions plus étendues à centre foncé, périphérie claire (Heath et Wood, 1969) et marge distincte non colorée (Dixon, 1988). Cet ensemble caractérisant les lésions évolutives dues à $M$ pinodes, il convient alors de provoquer l'apparition de pycnides en chambre humide afin de déterminer leur localisation. La présence de $P$ medicaginis peut être précisée, d'après les dimensions et le cloisonnement des pycnospores (Punithalingam et Gibson, 1976). 
En résumé, nous proposons la clef de détermination suivante :

- nécroses ou stries brunes, parfois très rapprochées sur l'épiderme, visibles à la base de la tige; présence ou absence de macules sur limbes :

- présence de macules sur les limbes; macules sombres coalescentes avec zonation concentrique lorsqu'elles dépassent $2 \mathrm{~mm}$ de diamètre; présence de pycnides sombres de 100-200 $\mu \mathrm{m}$, réparties suivant la zonation; cirrhes peu colorés d'apparence fluide s'étalant dès leur sortie par l'ostiole de la pycnide; pycnospores toutes cloisonnées, de longueur moyenne supérieure à 12 $\mu \mathrm{m}$ et présentant une constriction au niveau du septum; macules portant souvent des périthèces; ascospores bicellulaires, incolores et de $17 \mu \mathrm{m}$ de longueur moyenne : il s'agit de Mycosphaere/la (Ascochyta) pinodes;

- absence habituelle de macules sur les limbes; pycnides de dimensions très variables; pycnospores rarement cloisonnées, de longueur moyenne inférieure à $10 \mu \mathrm{m}$ et ne présentant pas de constriction au niveau du septum : il s'agit de Phoma medicaginis (var pinodella);

- pas de stries à la base de la tige; présence constante de macules sur les feuilles et parfois sur la tige au-dessus du premier nœud; macules claires bien délimitées par une marge brune, portant des pycnides $(100-200 \mu \mathrm{m})$ brun-roux, plus ou moins groupées au centre; cirrhes en apparence pâteux, émis d'une seule coulée par l'ostiole de la pycnide; pycnospores toutes cloisonnées de longueur supérieure à $11 \mu \mathrm{m}$ et ne présentant pas de constriction nette au niveau du septum; macules d'aspect parcheminé sur limbe, très marquées et déprimées sur entre-nœuds, normalement chancres sur gousses, symptômes parfois diffus : il s'agit de Ascochyta pisi.

II est toutefois impossible d'obtenir une certitude dans quelques situations : l'absence, normale, de pycnides sur les nécroses du pied : l'identification d'une association $M$ pinodes, $P$ medicaginis var pinodella repose alors sur les caractéristiques du thalle observées in vitro; le défaut de croissance n'est pas alors un critère absolu d'absence d'une espèce; en cas d'infections simultanées du même organe par $M$ pinodes et $A$ pisi : la discrimination à partir de l'examen de pycnospores est rendue aléatoire par la similitude des mensurations chez les deux espèces.

II n'existe encore aucune technique rigoureuse de diagnostic rapide. Toutefois, l'approche immu- nologique comme l'utilisation de sondes à ADN pourraient apporter une solution à ce problème (Madosingh et Wallen, 1968; Lawyer, 1984).

\section{Répercussions des anthracnoses sur les récoltes}

Wallen (1974) définit les facteurs du rendement affectés par chacun des parasites. Par des infections artificielles effectuées au champ dès la levée, il peut évaluer la progression hebdomadaire de la maladie sur les différents organes de la plante. Le rendement est estimé par le poids de gousses vertes. Les pertes atteignent $50 \%$ sur les parcelles inoculées avec $P$ medicaginis et $M$ pinodes; elles sont négligeables avec $A$ pisi.

Par les sévères pourritures qu'il occasionne au niveau des racines, $P$ medicaginis est le plus nuisible des trois parasites, quant à la destruction des jeunes plantules (fonte de semis) (Noll, 1940). Le peuplement peut diminuer de $24 \%$. Les organes aériens sont affaiblis et le nombre de gousses est réduit. $M$ pinodes est à l'origine de dégâts voisins. Toutefois, les contaminations secondaires liées aux ascospores entraînent, finalement, une défoliation apicale prématurée caractéristique.

Au champ, les infections sont d'autant plus efficaces qu'elles coïncident avec les stades phénologiques particulièrement décisifs quant au rendement de la culture (levée ou post-floraison).

L'infection précoce de l'appareil aérien (à la suite d'une dissémination d'ascospores de $M$ pinodes) se révèle être la cause principale de la diminution du rendement et de la moindre qualité des semences. L'incidence d'une attaque relativement tardive des gousses paraît moins évidente.

Avec $A$ pisi, seules les infections primaires entraînent une réduction du peuplement. La contamination des semences dont elle est responsable est plus élevée, cependant, cette espèce semble moins dommageable que les deux autres, souvent associées avec les infections secondaires au niveau du collet (Wallen, 1965).

\section{BIOLOGIE DE L'INFECTION}

\section{Propriétés biologiques des trois parasites}

La reproduction asexuée des trois espèces pathogènes pour le pois s'effectue par des pycnos- 
pores, hyalines, ellipsoïdes, souvent bicellulaires, expulsées dans un mucus.

$A$ pisi ne produit pas de chlamydospores, et ne présente pas sa forme de résistance de type microsclérote (Punithalingham et Holliday, 1972).

$P$ medicaginis var pinodella (Punithalingham et Gibson, 1976) est caractérisé par une abondante production de chlamydospores aussi bien in vitro que dans les tissus de l'hôte.

$M$ pinodes (Punithalingham et Holliday, 1972) dispose de quatre types de propagules : des pycnospores, des ascospores (Linford et Sprague, 1927; LK Jones, 1927b), des chlamydospores (Kerling, 1949); des microsclérotes (Dickinson et Sheridan, 1968) au niveau des tissus superficiels. L'existence d'une forme sexuée n'est reconnue que pour cette espèce.

In vitro, les trois champignons manifestent des caractères stables qui permettent leur distinction. En raison d'une abondante formation de chlamydospores et de pycnides, les cultures de $P$ medicaginis sont brun noir verdâtre. Celles de $M$ pinodes sont variables et généralement moins foncées. Sur milieu avoine, A pisi sécrète (Noll, 1939) des pigments jaunes et engendre des pycnides claires émettant des cirrhes de couleur rose. Leur croissance optimale se situe respectivement entre 24 et $28^{\circ} \mathrm{C}$ pour les deux premiers et $20-24{ }^{\circ} \mathrm{C}$ pour $A$ pisi. La genèse des pycnides est plus importante à la lumière et est stimulée par le transfert des cultures de $24^{\circ} \mathrm{C}$ à $4-8^{\circ} \mathrm{C}$, pendant un minimum de $5 \mathrm{j}$.

Les modalités de germination des pycnospores sont analogues pour les trois espèces. Au niveau des feuilles, la germination exige de l'eau liquide, surtout entre la $6^{\mathrm{e}}$ et la $12^{\mathrm{e}}$ heure (Hare et Walker, 1944). A pisi supporte des températures inférieures à $10^{\circ} \mathrm{C}$. $M$ pinodes attaque entre 10 et $30^{\circ} \mathrm{C}$, l'optimum d'agressivité étant noté entre 15 et $18^{\circ} \mathrm{C}$ (Wallen, 1965).

Chez $M$ pinodes, Ondrej (1973) observe une corrélation entre certaines caractéristiques des isolats, appréciées sur milieu avoine (vitesse de croissance réduite du mycélium, faibles dimensions des pycnides, sporulation intense) et pouvoir pathogène sur pois.

Partant de pycnospores de $M$ pinodes, Hare et Walker (1944) notent, sur milieu Potato Dextrose Agar, l'existence d'asques mûrs après 25$30 \mathrm{j}$ de culture à l'optimum thermique de $16^{\circ} \mathrm{C}$. En serre, le délai minimal observé entre infection et maturité des ascospores, n'est que de $13 \mathrm{j}$. Au champ, si l'humidité est suffisante, la formation des périthèces est facilement observée sur les extrémités en voie de maturation de la plantehôte.

Jones (1927b) obtient le stade sexué en partant d'une seule ascospore de $M$ pinodes. Hare et Walker (1944) obtiennent le même résultat à partir de 277 ascospores isolées de 40 asques et à partir de 69 pycnospores descendant de 2 ascospores différentes. Cette espèce est donc homothallique.

\section{Modalités de transmission de l'anthracnose}

\section{Transmission par la semence}

L'appréciation de l'état sanitaire des semences de pois est actuellement effectuée après incubation, selon les modalités standardisées par l'International Seed Testing Association (ISTA) (Anselme et Champion, 1962). De 1960 à 1978, le taux de contamination attribué en France à $M$ pinodes et $P$ medicaginis est presque toujours inférieur respectivement à $5 \%$ et $1 \%$, alors qu'il atteint $8 \%$ pour $A$ pisi (Anselme et Champion, 1971; Champion, 1978). Cependant, Champion et al (1984) signalent un taux de $47 \%$ de contamination par $M$ pinodes. $A$ pisi prédomine aussi dans les semences produites aux États-Unis (Linford et Sprague, 1927), en Grande-Bretagne (Hickman, 1941), au Canada (Skolko et al, 1954) et aux Pays-Bas (Dekker, 1957).

Linford et Sprague (1927) constatent l'implantation du mycélium de chacune des trois espèces au niveau des cotylédons. L'apparition de macules brunes sur les téguments, permet à Noll (1940) de localiser quelques contaminations profondes. Cependant, certaines ne peuvent être détectées que par une étude au laboratoire (Maude, 1966).

Dekker (1957) étudie l'influence de la contamination des semences sur le développement $d$ ' $A$ pisi. Partant d'un lot de semences (cv Eminence) contaminées à $80 \%$, cet auteur observe 10 à 15 j après semis sur sol stérile, une levée de $67 \%$. Parmi les plantules obtenues, une moitié seulement présente des symptômes typiques au niveau du premier nœud.

L'incubation en conditions stériles des divers éléments constitutifs de la semence permet de localiser le mycélium. Dans plus de $80 \%$ des cas, celui-ci traverse le tégument et atteint l'embryon une fois sur deux. 
Maude (1966) confirme ces résultats. La présence d'A pisi se manifeste entre la $2^{e}$ et la $4^{e}$ semaine après le semis. Sur un substrat stérile, elle concerne un maximum de $40 \%$ des planes issues de semences contaminées. Selon Wallen (1965), $25 \%$ de ces dernières présentent des pycnides.

Selon Dekker (1957), l'élimination du tégument de semences préalablement imbibées limite le taux de transmission de 17,5 à $5 \%$. La majeure partie des infections précoces résulterait donc de la progression du mycélium depuis les téguments jusqu'à l'embryon au cours de la germination. À $20^{\circ} \mathrm{C}$, l'invasion de celui-ci s'accomplit entre le $2^{e}$ et le $3^{e} \mathrm{j}$ après l'imbibition de la graine dormante. Une modification des conditions de milieu au cours de cette période déterminante pour la croissance du parasite se répercute sur la fréquence de colonisation de l'embryon alors à l'optimum de sa sensibilité.

Ainsi, une élévation de 21 à $28^{\circ} \mathrm{C}$ de la température du sol, réduit de moitié la fréquence des infections primaires. Cet effet est encore accentué entre 14 et $25^{\circ} \mathrm{C}$. Par ailleurs, avec l'étiolement de la tigelle qu'elles déterminent, les faibles intensités lumineuses sont défavorables à la transmission par la semence. II en résulte, comme l'observent Linford et Sprague (1927), qu'il est difficile de prévoir le nombre de foyers primaires d'A pisi dans les cultures.

Soixante-quinze pour cent des graines infectées par $A$ pisi proviennent de gousses envahies peu avant la maturité et atteintes de nécroses diffuses (Dekker, 1957). Enfin, l'examen des couches externes du cortex de l'épicotyle, situées au voisinage de lésions typiques, montre la présence de mycélium dans $40 \%$ des cas. Dans ces conditions, la contamination subméristématique de certaines tigelles pourrait aboutir à une infection non généralisée et à l'absence de tout symptôme. Ainsi en serait-il de la production de semences contaminées au sein de gousses apparemment saines.

Avec $M$ pinodes, $50 \%$ des attaques profondes des cotylédons s'extériorisent sous forme d'un brunissement des téguments (Maude, 1966). La désinfection des grains contaminés non tachés, par l'hypochlorite de sodium, ne détruit le mycélium que dans $75 \%$ des cas. Au cours du développement de la plante, le thalle progresse le long de l'axe à partir des isthmes cotylédonaires. Quelques individus sévèrement attaqués ne lèvent pas. Entre la $4^{\mathrm{e}}$ et la $5^{\mathrm{e}}$ semaine, 5 à $10 \%$ des infections primaires se manifestent par des lésions peu marquées au niveau des bractées de la gemmule (écailles). L'essentiel des infections primaires s'exprime à partir de la $6^{e}$ semaine, par des lésions au niveau du collet, d'où le mycélium gagne les écailles. Ajoutons que les dégâts résultant de la contamination par $M$ pinodes sont amplifiés par une altération de la vigueur germinative des semences, sous l'action de différents saprophytes (Jones, 1927b).

Bien qu'associé à une prolongation sensible de la période de latence, le rapport «fréquence des infections primaires/fréquence de semences contaminées" est plus élevé pour $M$ pinodes que pour $A$ pisi. Pour $M$ pinodes, un taux de contamination relativement faible par rapport à $A$ pisi est compensé par une forte agressivité. Aussi, l'état sanitaire des semences est-il un facteur important de la transmission de $M$ pinodes.

\section{Transmission par les restes de culture. Rôle des ascospores et des chlamydospores}

À condition qu'ils soient protégés des intempéries, les périthèces de $M$ pinodes engendrés peu avant la récolte sur les organes apicaux peuvent assurer la conservation hivernale de cette espèce (Hare et Walker, 1944). D'après ces auteurs, de telles fructifications ne sont plus fonctionnelles à l'approche du printemps, mais de nouvelles pycnides se forment vers le 15 mai sur les débris de cultures de l'année précédente, et des périthèces apparaissent à partir du mois suivant. Aux Pays-Bas, les périthèces initiés à la fin de l'été ne survivent qu'à la faveur d'hivers rigoureux. Toutefois, après un hiver doux, les gelées printanières favorisent l'apparition d'une nouvelle génération de ces organes sur les plantes (volunteer) issues de graines abondonnées sur le sol (Kerling, 1949).

Dans les conditions hivernales d'une serre non chauffée, Carter et Moller (1961) constatent une survie de 16 sem pour certains asques apparus sur des restes de culture. Dans un sol saturé d'eau, cette survie est seulement de $3 \mathrm{j}$ entre 28 et $33^{\circ} \mathrm{C}$, les ascospores se transformant alors en chlamydospores.

Les ascospores transportées par les turbulences atmosphériques sont susceptibles de transmettre $M$ pinodes à des cultures éloignées. Elles assurent ainsi l'extension de ce parasite dans les régions productrices de pois. Après des précipitations, Hare et Walker (1944) parviennent à capter des ascospores infectieux jusqu'à $300 \mathrm{~m}$ de leur site d'émission. D'après Lawyer (1984), la migration par voie aérienne atteindrait même $1600 \mathrm{~m}$. 
La transmission par ascospores peut être importante dans les zones où se pratiquent des semis échelonnés, et lorsque les semis d'automne ne sont pas précédés par une destruction des résidus de la récolte précédente. II en est ainsi dans le sud-ouest de la France, où les pois "d'hiver" (Cousin et al, 1985) semés généralement en novembre, sont fortement attaqués par $M$ pinodes. Cette situation est déjà reconnue par Weimer (1947) en Georgie (États-Unis). De telles conditions ne semblent pas réunies dans les régions ne produisant que des pois de printemps.

L'enrichissement d'un substrat en chlamydospores de $M$ pinodes et $P$ medicaginis à l'aide de débris de culture contaminés enfouis lors d'une expérimentation ad hoc ou à l'occasion d'une surculture permet d'observer des infections primaires du pied (footrot). Ainsi, pour expliquer la persistance de $M$ pinodes au Canada occidental, malgré l'utilisation de semences certifiées, Wallen et al (1967) font appel aux capacités de survie des chlamydospores dans le sol.

Un comptage réalisé par Wallen et Jeun (1968) montre encore que le nombre de propagules de $P$ medicaginis (voir également Gould, 1949 ) et de $M$ pinodes dans le sol augmente après une culture de pois.

Dans 18 situations sur 46 , les isolats de $P$ medicaginis sont de beaucoup les plus fréquents. Ils se révèlent antagonistes des deux autres espèces. Les souches les plus agressives sont fournies par les sols maintenus entre 5 et $10^{\circ} \mathrm{C}$. En raison du nombre élevé de ses chlamydospores et également de sa polyphagie (Dorenbosch, 1970; Bouznad, 1989), le maintien de ce parasite dans une parcelle cultivée en pois est assuré pour plusieurs années. Aucun cultivar n'étant actuellement résistant et aucun traitement n'étant polyvalent, les attaques du pied deviennent plus fréquentes.

Remarques - Dickinson et Sheridan (1968), puis Sheridan (1973) constatent le déclin de la population de propagules de $M$ pinodes dans un sol à partir de $10^{\circ} \mathrm{C}$. Mais celui-ci cesse dès que la température est fixée au-dessous de $2^{\circ} \mathrm{C}$.

$A$ pisi qui ne produit pas de chlamydospores et ne conserve son agressivité que s'il hiverne à une température inférieure à $20^{\circ} \mathrm{C}$, n'est pas isolé des sols de culture.

\section{Conséquences pratiques}

Selon Anselme et al (1970), des semences appartenant à quatre cultivars, et présentant un taux de contamination par $A$ pisi compris entre 2 et $6 \%$, entraînent l'apparition au champ, de foyers primaires sur 0,5 à $4 \%$ des plantes. En lle-de-France, le taux de contamination tolérable serait de $5 \%$. D'après les résultats de Wallen (1965) qui mettent en relation le pourcentage de contamination des lots et les pertes de rendement qui résultent de leur utilisation, et compte tenu de l'agressivité respective des espèces d'Ascochyta, Neergaard (1979, p 837) considère comme économiquement acceptables pour $A$ pisi des fréquences de contamination des semences quadruples par rapport à $M$ pinodes (doubles si l'on considère $P$ medicaginis). D'après Wallen (cité par Neergaard, 1979), au Canada, les pourcentages tolérés pour la semence de base étaient en 1970 de $6 \%$ pour $A$ pisi et de $2 \%$ pour les deux autres parasites réunis.

Le transfert depuis 1915 des zones productrices de semences vers les États à climat semiaride de l'ouest des États-Unis, a permis de réduire la fréquence d'A pisi. Une épidémie survenue en 1941 dans l'ouest confirme l'hypothèse de la transmission de ce parasite par les semences. En effet, la maladie connut une recrudescence en 1942 et 1943, dans le Wisconsin très éloiigné des régions productrices de semences (Hare et Walker, 1944).

La transmission par la semence est aussi incriminée (Skolko et al, 1954), dans le cas de variétés considérées comme tolérantes à $A$ pisi, en raison de l'extension réduite des macules sur le feuillage. En fait, celles-ci présentent, au niveau des gousses, une sensibilité particulière à ce parasite.

Au Canada, Wallen et al (1967) signalent un cas complexe de transmission consécutif à l'introduction du cultivar "Century" résistant à $A$ pisi, mais seulement tolérant à $M$ pinodes. On observe alors une recrusdescence de l'attaque des gousses par ce dernier. L'interprétation doit prendre en considération la persistance de $M$ pinodes dans le sol. Comme $P$ medicaginis, ce parasite devient endémique dans les régions où le pois entre fréquemment dans la rotation.

\section{Infections secondaires}

L'importance d'une attaque par $M$ pinodes semblerait modulée par l'humidité requise, particulièrement lors de l'extension des macules où sont formés pycnides et périthèces, mais aussi lors 
de la dissémination des ascospores et des infections apicales qu'elles engendrent (Jones, 1927b; Hare et Walker, 1944; Kerling, 1949; Chup et Sherf, 1960).

\section{Dissémination des pycnospores liée à des éclaboussements (splashing)}

Une fois constitués les foyers primaires, les différentes espèces d'Ascochyta se propagent par des infections secondaires à l'origine desquelles on trouve, au moins dans une première phase, plusieurs générations successives de pycnospores (Hare et Walker, 1944).

Pour en décrire la dispersion, nous disposons du modèle proposé par Gregory et al (1959). À l'occasion de précipitations, un film aqueux se constitue à la face supérieure des organes nécrosés porteurs de pycnides. Le mucus renfermant les pycnospores se dilue dans ce film d'où la pluie expulse des gouttelettes d'inoculum (splashing). Celles-ci sont alors entraînées par des turbulences dues au vent.

Dekker (1957) étudie la propagation d'A pisi, dans un peuplement normal de pois, à partir de plantes issues de semences infectées. Pour une parcelle exposée au vent, la dissémination primaire des pycnospores est de l'ordre de $20 \mathrm{~cm}$ en moyenne et ne dépasse pas $65 \mathrm{~cm}$ dans le sens des vents dominants ( 7 et $12 \mathrm{~cm}$ dans une parcelle relativement abritée). À partir d'un foyer de 50 plantes, l'extension du parasite est de l'ordre de $3,5 \mathrm{~m}$ après 12 sem de culture ( 4 générations filles progressant par étapes). Toutefois la dissémination des seules pycnospores ne peut rendre compte des invasions sévères des nœuds apicaux par $M$ pinodes. L'importance de ce parasite est liée à la dispersion de ses ascospores par voie aérienne.

\section{Transport des ascospores par voie aérienne}

Le mécanisme de l'éjection des ascospores de $M$ pinodes est décrit par Stone (1912). Après humidification du périthèce, la paroi externe de l'asque mûr inséré dans l'ostiole se déchire sous la pression de la paroi interne distendue. Les ascospores sont alors projetées jusqu'à une distance de 2 à $3 \mathrm{~mm}$. Le mécanisme fonctionne entre 0 et $37^{\circ} \mathrm{C}$.

L'application par aspersion d'une quantité d'eau supérieure ou égale à $1,8 \mathrm{~mm}$ à des résidus de récolte, permet à Carter et Moller (1961) d'obtenir la libération des ascospores $30 \mathrm{~min}$ plus tard. Celle-ci peut durer de 50 à $60 \mathrm{~min}$. La charge de l'air en ascospores, nulle par temps sec, devient considérable à l'occasion de précipitations. Ainsi, Hare et Walker (1944) dénombrent jusqu'à 8 ascospores $/ \mathrm{cm}^{2}$ de feuillage à plus de $300 \mathrm{~m}$ de leur foyer d'émission.

D'après LK Jones (1927b), et pour l'État de New-York, 51 à 55 j s'écoulent à partir du semis avant que des ascospores n'arrivent à maturité au sein de la culture. Chez les jeunes plantes, les surfaces nécrosées susceptibles d'héberger des périthèces mûrs sont peu nombreuses et la dissémination ne devient vraiment importante qu'à partir d'un stade plus avancé (floraison). L'apparition de criblures caractéristiques sur les limbes des dernières feuilles implique l'intervention d'ascospores entraînées par les vents dominants humides. La généralisation de la maladie est alors à craindre.

Pour apprécier la dynamique d'une population de $M$ pinodes, Kerling (1949) propose une échelle de notation complexe qui tient compte de la superposition de 3 processus : la croissance des lésions évolutives aboutissant à la formation des pycnides (paramètre modulé par la durée relative des condensations sous le couvert); la sénescence accélérée des organes contaminés; la périodicité d'émission des ascospores.

\section{GENÈSE ET ASPECT DES MACULES PROVOQUÉES PAR A PISI ET M PINODES}

Les nécroses provoquées chez le pois par $A$ pisi et $M$ pinodes prennent souvent l'aspect de macules à croissance limitée. Heath et Wood $(1969,1971 a, b)$ considèrent les interactions du cv Onward avec ces 2 parasites. Ils étudient l'influence de 3 paramètres sur l'infection: hydratation et maturité des tissus, nombre de pycnospores par gouttelette infectieuse. L'observation en microscopie électronique associée à l'histologie classique (coloration, localisation de la biréfringence et de la plasmolyse) permettent de mettre en relation l'activité du parasite avec les réponses de l'hôte.

\section{Lésions provoquées par A pisi}

Environ 24 à $48 \mathrm{~h}$ après le contact des pycnospores avec la surface du limbe, une hyphe pénétrante issue d'un appressorium franchit la cuti- 
cule, généralement à la jonction de deux cellules épidermiques (il est probable que des cutinases sécrétées par le parasite participent à la perforation de la cuticule). Deux jours plus tard, des hyphes franchissent l'épiderme entre deux cellules. La ramification du thalle dans les méats s'accompagne d'un collapsus des tissus superficiels (Brewer et MacNeill, 1953). Le diamètre de la macule foliaire est en rapport avec l'importance du thalle sous-cuticulaire (Bouznad, 1989).

À son début, la colonisation du parenchyme est principalement intracellulaire. Les cellules ne brunissent pas, mais se vacuolisent et dégénèrent, souvent à quelques distance des hyphes. Le parenchyme perd sa cohésion en raison de modifications au niveau des lamelles moyennes pectiques, le cytoplasme devient hétérogène, et le plasmalemme se dégrade (Heath et Wood, 1969).

L'invasion du limbe s'exprime, entre les $5^{e}$ et $8^{\mathrm{e}} \mathrm{j}$, par des infiltrations lenticulaires et opaques (Lawyer, 1984). Chaque lésion brun clair atteint au bout de $8 \mathrm{j}$ un diamètre de $2,0 \mathrm{~mm}$ (extension maximale entre 0,25 et $0,48 \mathrm{~mm} / \mathrm{j}$ ). L'abrasion des cires cuticulaires réduit la période d'incubation. Les tissus situés à l'extérieur de la marge brune ni lignifiée ni subérifiée, sont réfractaires à l'implantation de lésions secondaires.

\section{Macules évolutives dues à M pinodes}

Un appressorium et une hyphe pénétrante interviennent également dans l'attaque de la cuticule (Heath et Wood, 1969). Selon Kerling (1949), la pénétration par les orifices stomatiques est relativement fréquente et le thalle sous-cuticulaire beaucoup moins développé qu'avec $A$ pisi. La progression intercellulaire des hyphes dans le parenchyme cortical de l'épicotyle, s'effectue sans dégradation de la lamelle moyenne. Elle s'accompagne de dépôts de matériaux pectiques qui semblent en relation avec l'inhibition de certaines hyphes au niveau des méats.

Selon Clulow et al (1991a,b), le franchissement de la cuticule de l'épicotyle fait intervenir certains enzymes d'origine fongique. Trois jours après le début de l'incubation, les cellules parasitées de l'épiderme brunissent et deviennent inaptes à la plasmolyse.

Linford et Sprague (1927) montrent que l'infection des limbes s'extériorise 48 à $72 \mathrm{~h}$ après l'inoculation, par l'apparition de macules brun foncé d'environ $1 \mathrm{~mm}$ de diamètre. En atmos- phère saturée et en présence de 1 à 25 spores, cette criblure sans marge nette, peu favorable à la genèse des pycnides, se stabilise (Heath et Wood, 1969). Contrairement à ce qui est observé avec $A$ pisi, les nécroses d'abord superficielles (ponctuations sur limbes et gousses, stries sur pétioles, nervures et entre-nœuds) entrent en coalescence. Au niveau cellulaire, les composés pectiques s'accumulent dans les parois dont l'épaisseur passe de 0,205 à 0,396 $\mathrm{m \mu}$.

Cependant, sur des folioles maintenues en contact avec l'eau, on note le développement d'un halo verdâtre translucide autour des criblures originelles brun foncé. Celui-ci s'étend pendant plusieurs jours à une vitesse qui, dans le cas d'une forte inoculation, peut atteindre 2,4 $\mathrm{mm} / \mathrm{j}$. La périphérie de la macule et les nervures paraissent particulièrement propices à la genèse de pycnides qui se distribuent selon des auréoles concentriques. Dans ces lésions évolutives (progressive ou spreading d'après Heath et Wood, 1969), l'épaisseur des parois pectocellulosiques des cellules (peu colorées par le rouge de ruthénium) ne dépasse pas $0,094 \mu \mathrm{m}(0,220 \mu \mathrm{m}$ pour $A$ pisi).

Au $8^{e} \mathrm{j}$, le diamètre des lésions est 4 fois supérieur à celui observé pour les témoins maintenus en atmosphère saturée. Il est ainsi 3 à 6 fois plus important que celui des macules provoquées par $A$ pisi. Une hydratation moyenne se traduit pas une vitesse de progression intermédiaire. Des conditions d'hydratation maximale peuvent donc lever l'inhibition du thalle de $\mathrm{M}$ pinodes localisé à la périphérie de la zone "criblée". Ajoutons que l'importance de l'inoculum comme le choix de folioles âgées sont autant de conditions favorables à l'apparition des lésions évolutives et que cette accélération des phénomènes nécrotiques peut encore survenir entre le $g^{\mathrm{e}}$ et le $14^{\mathrm{e}} \mathrm{j}$.

\section{Dégradation enzymatique des parois}

L'étude à l'échelle microscopique de la pénétration et de la colonisation suggère que les enzymes de macération interviennent, bien qu'avec des modalités différentes, dans la genèse des lésions limitées causées par $\boldsymbol{A}$ pisi et dans celles des lésions évolutives liées à l'action de $M p i$ nodes. Elles n'interviennent pas dans le cas des criblures. Heath et Wood (1971a) précisent les mécanismes de dégradation des parois au niveau des macules par l'observation du paren- 
chyme de disques foliaires soumis à des extraits enzymatiques et évaluent l'accumulation d'inhibiteurs des enzymes extraits.

La perte de cohésion entre cellules qui résulte de la dégradation de la lamelle moyenne et de son voisinage est qualifiée de macération. La structure primaire des parois étant affectée, celles-ci ne peuvent plus supporter la pression impliquée par le protopiasme qui se nécrose. Les deux processus sont attribués à l'action directe des enzymes extraits (Endo hydrolases et transéliminases ou lyases) sur la fraction rhamnogalacturonique des parois (Bateman et Basham, 1976; Bateman, 1976). Ce syndrome, qui constitue un stade primordial de l'établissement d'une relation trophique avec le parasite, est observé pour de nombreuses maladies occasionnées par des parasites facultatifs.

Les extraits provenant des lésions (limitées) dues à $A$ pisi, manifestent des activités pectinolytique et hémicellulolytique. La perte de cohésion des tissus provoquée par la transéliminase est indiscutable, mais le rôle de la polygalacturonase paraît moins évident. Les extraits renferments également des inhibiteurs de ces enzymes. En outre, au niveau de la marge brune, la macération s'interrompt. Cette résistance est mise en relation soit avec l'inactivation in situ des enzymes pectinolytiques (Deverall et Wood, 1961), soit avec une modification dans le temps de la structure secondaire de la paroi (Kuc et al, 1967; Nevins et al, 1968). Elle semble jouer un rôle important dans la limitation des macules provoquées par ce parasite.

Les extraits de lésions causées par $M$ pinodes renferment des enzymes cellulo-, hémicelluloprotéo- et pectino-lytiques. Cependant, dans le cas de folioles maintenues à la surface de l'eau, la dégradation des parois ne se manifeste qu'à la marge des lésions évolutives et sans brunissement. Les extraits enzymatiques responsables de la macération à ce niveau, ne présentent plus d'activité en présence des tissus bruns épaissis, caractéristiques des lésions limitées. Cependant, ces dernières recèlent non seulement une activité enzymatique réduite, mais encore des inhibiteurs aquasolubles de la transéliminase.

Huit jours après le début de l'incubation, la teneur en phénols est 4 fois plus forte au niveau des lésions limitées. Cependant, alors que la teneur en polyphénols des tissus infectés reste comparable à celle des témoins (Heath et Wood, 1971a), la croissance des lésions évolutives sur folioles flottantes s'accompagne de la diffusion dans le support aqueux de composés vraisemblablement quinoniques, de couleur brune. La nécrose liée à une active macération se développe alors sans brunissement. Toutefois, la rupture des parois ne semblant liée qu'à des modifications de pression, Heath et Wood (1969) en concluent que les différences de croissance des plus jeunes thalles selon les conditions d'hydratation, ne semblent pas imputables à un dépôt, au niveau des parois, d'inhibiteurs quinoniques des enzymes de macération.

Par ailleurs, les auteurs constatent que le pourtour des lésions évolutives dues à $M$ pinodes est plus résistant à la macération que celui des lésions limitées. Vue la rapidité avec laquelle les parois cellulaires y sont dégradées lors de la progression des lésions évolutives, la croissance du parasite ne semble pas affectée de manière significative par des variations dans la résistance des tissus à la macération.

En résumé, l'extension des nécroses provoquées par $M$ pinodes ne dépend pas principalement de la macération des parois. Aussi, la cause de la limitation des macules ne doit pas être recherchée dans l'inhibition de la transéliminase par les polyphénols. Le facteur limitant la croissance de $M$ pinodes serait constitué par un ou plusieurs inhibiteurs de la croissance fongique.

\section{Régulation de la croissance des macules provoquées par A pisi et M pinodes}

\section{Induction de la réponse active. Inducteurs et suppresseurs. Application à la pisatine}

La réponse d'une plante à l'agression par un micro-organisme fait intervenir le métabolisme de l'hôte. Elle doit être induite. Partant de faits d'ordres génétique et physiologique, Keen (1982) énonce la théorie généralement admise d'un modèle «inducteur-récepteur d'induction»: élicitation. Divers modèles physiologiques à implications génétiques ont été proposés; leur objectif est d'interpréter l'ensemble complexe des relations gène-pousr-gène.

La fixation de l'inducteur sur un récepteur de I'hôte localisé au niveau membranaire constitue un signal de reconnaissance transmis jusqu'au noyau de la cellule-hôte. Ce signal est converti en un enchaînement d'événements métaboliques qui traduit la réponse de l'hôte (de Wit, 1986). 
L'induction des mécanismes de réponse a été obtenue expérimentalement à l'aide de composés isolés de parois cellulaires, filtrats de culture, cytoplasme de micro-organismes. Parmi les inducteurs de la défense active des plantes, Collmer et Keen (1986) mettent l'accent sur les fragments de nature oligogalacturonique (inducteurs de constitution) libérés précocement par la macération enzymatique des parois. En outre, Keen et Legrand (1980), Keen et al (1983) montrent que certains constituants structurels (glycoprotéines et glucomannanes) des parois de Phythophthora megasperma, joignent à leur potentiel d'éliciteur de phytoalexine une capacité de médiateur de la spécificité gène-pour-gène.

Les réponses de défense les mieux connues sont celles qui aboutissent à l'accumulation des phytoalexines ou à la réponse d'hypersensibilité. Les phytoalexines sont des "composés antimicrobiens de faible poids moléculaire synthétisés par la plante et s'y accumulant à l'occasion d'une interaction entre cette plante et un microorganisme" (Paxton, 1981). Ce type de composé apparaît également à la suite de stress d'origine chimique ou physique (Rouxel, 1989).

C'est à l'occasion des interactions au sein d'un couple non compatible que les phytoalexines atteignent rapidement des concentrations inhibitrices entraînant la résistance de la plante hôte.

La pisatine, principale phytoalexine du pois (Ingham, 1982), appartient au groupe des isoflavonoïdes et fut isolée par Cruickshank et Perrin (1960, 1961). Cruickshank (1962) montre qu' $A$ pisi est plus tolérant à la pisatine qu'un ensemble de champignons non parasites du pois. L'endocarpe du pois infecté par $A$ pisi en renfermant plus de $1000 \mu \mathrm{g} \cdot \mathrm{ml}^{-1}$, elle contribuerait à limiter l'extension des macules provoquées par ce parasite (Cruickshank et Perrin, 1965). D'après Hadwiger et al (1981), l'induction de la pisatine au cours des interactions Fusarium solanif $\mathrm{sp}$ pisi Snyd et Hans/Pisum sativum serait réalisée par un chitosane (polymère de $\beta$ 1-4 glucosamine) constituant des parois des spores de Fusarium. D'après Shiraishi et al (1978a), bien que les tubes germinatifs des pycnospores de $M$ pinodes se révèlent tolérants à la pisatine, celleci inhibe l'installation des hyphes dans l'épiderme de Pisum sativum. Les sécrétions des spores durant leur germination renferment à la fois des glucanes, des glycoprotéines de poids moléculaire supérieur à $70000 \mathrm{Da}$, des inducteurs (non spécifiques) de la pisatine, des anta- gonistes spécifiques de l'induction de la pisatine, et des suppresseurs (Shiraishi et al, 1978b).

Les difficultés rencontrées dans l'isolement d'inducteurs spécifiques ont conduit certains chercheurs à développer ce dernier point. Lors d'une première phase des interactions compatibles, le pathotype virulent libérerait des suppresseurs capables d'annuler l'induction non spécifique (Heath, 1981). L'un d'entre eux (Shiraishi et al, 1978b) de masse moléculaire inférieure à $5000 \mathrm{Da}$, administré à différentes légumineuses, confère à une espèce d'Alternaria parasite du poirier, un spectre de compatibilité identique à celui de $M$ pinodes. Ce suppresseur pourrait donc être considéré comme un déterminant du pouvoir pathogène de ce champignon (Oku et al, 1980). On ne sait pas si cette substance agit par compétition au niveau des sites de reconnaissance spécifiques de l'inducteur de la phytoalexine ou par induction d'une réponse d'un autre type (Dixon et Lamb, 1990).

Les inducteurs non spécifiques sont à l'origine d'une résistance locale et rapide (moins de $2 \mathrm{~h}$ ) au niveau de l'épiderme, et d'une accumulation de pisatine plus tardive $(9 \mathrm{~h})$. Ces deux phases de réponse seraient inhibées par les suppresseurs secrétés par $M$ pinodes (Yamamoto et al, 1986).

L'un des suppresseurs dont la structure chimique n'est pas encore clairement établie, administré à des épicotyles de pois, retarde l'activation de la voie des phénylpropanoïdes (transcription des PAL- et CHS-mRNA). L'apparition de l'activité PAL est différée de $6 \mathrm{~h}$ et l'accumulation de pisatine de 6 à $9 \mathrm{~h}$ (Yamada et al, 1989).

\section{Inhibition du thalle par la pisatine. Levée de cette inhibition en présence d'eau}

Afin d'analyser l'inhibition de la croissance du parasite, Heath et Wood (1971b) déterminent les modifications de la teneur en pisatine au cours des processus nécrotiques décrits précédemment. L'activité inhibitrice des extraits de tissus est appréciée d'après la croissance de tubes germinatifs de $M$ pinodes.

In vitro, une concentration de $1000 \mu \mathrm{g} . \mathrm{ml}^{-1}$ entraîne chez $A$ pisi une inhibition de $90 \%$. Le comportement de $M$ pinodes en présence de la même concentration dépend des conditions expérimentales (quantité de mycélium impliquée et des éléments nutritifs disponibles dans le milieu de culture). 
Dans les tissus colonisés par $A$ pisi l'accumulation de la pisatine se poursuit du $1^{\mathrm{er}}$ au $14^{\mathrm{e}} \mathrm{j}$ après le début de l'incubation. Au niveau de la marge brune (où, le thalle étant absent, la dégradation ne peut pas se produire), la concentration atteint $1700 \mu \mathrm{g} \cdot \mathrm{ml}^{-1}$ de tissu frais. Une telle teneur à la périphérie de la région colonisée semble suffisante pour expliquer la limitation des lésions occasionnées par ce parasite.

Après infection par $M$ pinodes, on observe dans le cas des lésions limitées placées en atmosphère saturée, une teneur en pisatine de 2000 à $3600 \mu \mathrm{g} \mathrm{g}^{-1}$ au $2^{e} \mathrm{j}$ alors que le champignon est encore dans l'épiderme. Elle n'est plus que de $500 \mu \mathrm{g} . \mathrm{g}^{-1}$ entre le $5^{\mathrm{e}}$ et le $8^{\mathrm{e}} \mathrm{j}$. Les tissus entourant la lésion sont alors appauvris en éléments nutritifs.

Sur folioles flottantes, la teneur en pisatine au niveau des jeunes lésions provoquées par $M$ pinodes passe de 800 à $600 \mu \mathrm{g} \cdot \mathrm{g}^{-1}$ entre le $1 \mathrm{er}$ et le $2^{\theta} \mathrm{j}$. Elle décroît ensuite rapidement, alors que l'on observe une accélération de la croissance des lésions.

Heath et Wood (1971b) envisagent qu'une dégradation enzymatique de la pisatine par le parasite est liée à l'extension des nécroses. La perte d'activité de cette molécule in vivo sous l'action de $M$ pinodes est démontrée par Platero, Sanz et Fuchs (1980), qui notent l'accumulation d'un dérivé déméthylé, faiblement actif, de la pisatine.

Heath et Wood (1971b) distinguent deux modalités principales d'interaction : d'une part, une réaction intense entraînant la formation d'une nécrose brune de type "criblure" et associée à une accumulation de pisatine, et d'autre part, une réaction affaiblie (sans brunissement), liée à une induction minimale de pisatine suivie d'une rapide dégradation de cette dernière, entraînant une nécrose "évolutive". Ces deux modalités peuvent se succéder dans des conditions variables de turgescence des cellules, et se matérialisent à la surface des organes parasités par une alternance de zones brunâtres et de zones vertes (Linford et Sprague, 1927). Ainsi, la vitesse de dégradation de la pisatine, comme la croissance des macules, seraient soumises aux conditions environnementales.

Les auteurs mettent en évidence deux conditions favorables à la dégradation de la pisatine accumulée au début de l'interaction avec $M$ pinodes (déméthylation adaptative, VanEtten, 1989): 1) un niveau élevé d'hydratation des nécroses ássocié à leur appauvrissement en éléments nutritifs; si celui-ci est insuffisant, la cou- verture des besoins trophiques du parasite (Pierre et Millar, 1965), et partant leur aptitude (cf plus haut) à se développer in vitro en présence de concentrations de pisatine élevées, n'est pas assurée; 2) l'intensité de l'attaque (une concentration importante du mycélium) au niveau des nécroses initiales : en fait, ce paramètre de l'infection dépend de la concentration de l'inoculum en pycnospores.

Ainsi, les différences entre tous les types de lésions, qu'elle soient provoquées par $M$ pinodes ou par $A$ pisi, peuvent être interprétées en termes de différences de sensibilité à la pisatine et de différences dans la rapidité de son inactivation.

Diverses conditions de la biosynthèse de novo de la pisatine rendent compte de cas particuliers d'interaction avec $M$ pinodes. Ainsi, la perte de l'aptitude de certains tissus à accumuler la pisatine s'accompagne-t-elle d'une exacerbation de leur sensibilité. C'est le cas pour la gousse proche de la maturité (Cruickshank et Perrin, 1963) et pour les limbes en phase de sénescence (Bailey, 1969). Kerling (1949) signale encore des réponses perturbées dans le cas d'organes de pois soumis à un excès d'humidité, à des gelées tardives ou traités par les narcotiques. Dans le cas «limite» où un limbe est infecté peu avant sa sénescence, Darby et al (1986) notent un accroissement de la vitesse d'extension des macules provoquées par $A$ pisi.

Cependant, un tel schéma ne suffit pas à rendre compte de la totalité des aspects de la pathogenèse.

Selon Lepoivre (1981, 1982a,b), les feuilles attaquées soit par $A$ pisi, soit par $M$ pinodes, renferment des quantités appréciables d'ascochitine. Celle-ci est une toxine isolée des filtrats de culture d'A pisi (Oku et Nakanishi, 1963) et d'A fabae Speg (Bertini, 1956) dont la structure benzopyrannique a été élucidée par Iwai et Mishima (1965). Lepoivre $(1981,1982 a, b)$ met en évidence une corrélation entre la sensibilité de différents cultivars à l'égard de ce composé et le diamètre moyen des macules provoquées par les deux champignons. II propose un modèle qui situe l'ascochitine parmi les composantes des interactions $A$ pisi/P sativum. Land et al (1975a, b) constatent que l'ascochitine se comporte dans les tissus comme un éliciteur de la pisatine. Le début de la phase nécrosante repéré par Clulow et al (1991a, b) pourrait coïncider avec la sécrétion d'ascochitine par le thalle de $M$ pinodes, mais la quantification de cette molécule dans les 
tissus ne peut pas encore être correctement effectuée.

\section{EXPRESSION ET TRANSMISSION HÉRÉDITAIRE DE LA RÉSISTANCE À A PISIET M PINODES}

LK Jones constate dès 1927 que la virulence des populations d'A pisi Lib diffère suivant la zone géographique de culture du pois. La possibilité de distinguer des pathotypes chez ce champignon est aujourd'hui largement confirmée.

Aucune technique ne permettant de limiter la transmission de la maladie, la sélection commencée en 1934 concerne d'abord la résistance à l'espèce d'Ascochyta la plus répandue, $A$ pisi (Lyall, 1949).

D'après Gilpatrick et Busch (1950), la lignée A-100 se révèle efficace vis-à-vis d'isolats d'origine variée. Brewer et MacNeil (1953) montrent que la résistance phénotypique de A-100 fait intervenir un facteur inhibant précocement l'installation de ce parasite. Wallen (1957) distingue, au sein des populations d'A pisi canadiennes, au moins 4 pathotypes inféodés chacun à une zone géographique. La confrontation réalisée par Lyall et Wallen (1958) de 375 descendants d'un croisement A-100 x Thomas Laxton (sensible) avec un isolat appartenant au pathotype II de Wallen, permet d'établir un rapport de ségrégation en F2 de 15 résistants pour 1 sensible. Ces auteurs concluent à l'intervention de deux facteurs dominants dupliqués.

Les pathotypes d'origine européenne B, C, D de Hubbeling (1972, p 162) semblent identiques aux pathotypes Hubbeling (1972, p 162) semblent identiques aux pathotypes II, III, IV de WalIen (1957). À partir du cv Rondo, Cousin (1972, p 149) isole une lignée dont la résistance à un grand nombre d'isolats d'A pisi, en particulier le pathotype $C$, semble régie par un gène majeur de dominance intermédiaire. Cette résistance ne concerne ni le pathotype $\mathrm{E}$ ni deux pathotypes isolés en France (Cousin et al, 1985, 127-128). Cependant, le cv Gullivert manifeste une bonne résistance vis-à-vis de ces derniers.

Malgré des différences concernant les modes opératoires, les gammes d'hôtes différentiels, et en dépit de l'utilisation de cultivars et non de lignées pures, les résultats précédents permettent de conclure à une stabilité des pathotypes d'A pisi dans une même aire de culture (Wallen et Cuddy, 1968).
La variabilité de la virulence chez $A$ pisi, mais aussi chez $M$ pinodes a récemment donné lieu à deux études systématiques portant sur un effectif suffisamment représentatif du patrimoine génétique du genre Pisum.

D'une part part, Darby et al (1986) étudient les effets de l'environnement sur l'expression de symptômes qui justifient la discrimination des isolats d'A pisi en pathotypes. D'autre part, Clulow (1991a, b) met en évidence une résistance à $M$ pinodes et il évalue pour la première fois la virulence et le pouvoir pathogène de ce parasite.

Cette utilisation d'hôtes différentiels est d'autant plus précieuse qu'aucune méthode d'analyse du génome de ces deux champignons n'est actuellement définitivement acceptée.

Darby et al $(1985,1986)$ observent et définissent à l'échelle microscopique une gamme de réponses traduisant l'ensemble des interactions $P$ sativum/A pisi.

Six degrés sont définis : le degré (0) est lié à l'inhibition de l'hyphe pénétrante; le degré (1) se manifeste par une hypersensibilité au point de rupture de la cuticule et un arrêt de la croissance de cette hyphe; le degré (5) s'exprime par un collapsus fréquent de la tige.

Par ailleurs, 14 lignées d'hôtes différentiels permettent de caractériser 5 pathotypes parmi 57 isolats représentant $A$ pisi en GrandeBretagne.

La persistance de la résistance conférée par le cv Rondo (Cousin et al, 1985) confirme la stabilité du système de virulence chez $A$ pisi. Enfin, les études d'hérédité, utilisant Jl 502 (cv Rondo) comme géniteur sans symptômes, montrent que cette réponse serait régie par un gène unique situé près du gène rap 2 commandant la réponse d'hypersensibilité (Darby et al, 1985). L'expression de ce gène de résistance sans symptômes n'est surmontée que par des pathotypes peu répandus. Elle présenterait un potentiel considérable si elle était associée à la réponse du gène d'hypersensibilité.

Les travaux concernant la résistance à $M$ pinodes sont en cours. L'infection de la tige étant plus dommageable pour le devenir d'une culture qu'une infection limitée au système foliaire, Clulow et al (1991a) proposent de caractériser les isolats par leur action au niveau du seul épicotyle. D'après le comportement de 9 hôtes différentiels, les auteurs distinguent actuellement 9 pathotypes au sein de 45 isolats (16 pathotypes 
d'après les symptômes foliaires). Deux lignées manifestent une résistance vis-à-vis de l'ensemble de ces isolats : elles pourraient être utilisées comme géniteurs de résistance.

\section{STRATÉGIE DE LUTTE CONTRE LES ANTHRACNOSES}

Tivoli et Lemarchand (1992) localisent les principaux problèmes sanitaires liés à la culture du pois. Ils confirment l'impact pratique de $M$ pinodes en France. Par son endémisme dans des environnements variés, cette espèce est l'agent d'anthracnose le plus redoutable.

Nous avons vu que la transmission de ce parasite s'effectue suivant les modalités suivantes :

- 1) attaques (infections primaires) des cotylédons et éventuellement de la tigelle avant maturité de la graine;

- 2) attaque de la tigelle après imbibition de la graine entre le semis et la levée, soit a) par des hyphes à l'état dormant présentes dans les cotylédons : on observe alors une attaque des isthmes (région de l'embryon assurant la connexion entre le cotylédon et la base de la tigelle) et, plus rarement, l'épicotyle ou les bractées embryonnaires; ou b) par des propagules adhérant aux téguments de la graine depuis la récolte ou encore conservées dans le sol depuis une précédente culture;

- 3) infections du bourgeon après la levée, à la suite du transport aérien des ascospores engendrées sur des plantes ou des résidus de la récolte précédente.

Les informations nécessaires pour caractériser l'évolution initiale de $M$ pinodes, comme les observations permettant de départager les modalités de transmission ci-dessus, font actuellement défaut. Aussi la stratégie de lutte les prend-elle toutes en compte.

Remarquons que la lutte développée contre $M$ pinodes s'applique aussi aux deux autres espèces qui ne disposent que d'une partie des capacités de conservation ou de dissémination de $M$ pinodes.

\section{MÉTHODES CULTURALES}

Les fanes et les résidus de récolte doivent être détruits ou enfouis rapidement après la récolte (voir $2 \mathrm{~b}$ et 3 ci-dessus). Si des attaques par $P$ medicaginis sont à craindre, il convient d'allonger le cycle de rotation (Lawyer, 1984) en ajoutant une ou deux cultures intermédiaires.

La production de semences, et en particulier de semences de base, devrait être assurée par des exploitations ne pratiquant pas la culture du pois à des fins industrielles ou alimentaires, et situées dans les régions où le climat rend peu probable une succession de précipitations à partir de la floraison. L'échelonnement des semis doit être évité et la récolte effectuée dès la maturité du grain ( 1 et $2 a$ ).

L'objectif d'une certification serait de garantir l'utilisateur contre les éventualités 1 et 2 et elle concernerait aussi d'autres agents pathogènes transmis par la semence : PSbMV (pea seedborn mosaic virus) et Pseudomonas syringae pv pisi.

\section{Sélection du pois quant à sa résistance aux anthracnoses}

Pour prévenir la transmission par les semences et assurer la protection des semis en présence d'inoculums telluriques, la méthode la plus efficace réside dans la création de cultivars durablement résistants au moins lors des premiers stades phénologiques. Des progrès récents dans la maîtrise de la résistance à $M$ pinodes, justifient l'opinion de Hagedorn (1985) concernant de nouvelles possibilités d'utilisation pratique de la résistance dans les pois "potagers".

La résistance manifestée par certaines lignées (Clulow et al, 1991) doit être confirmée en présence des pathotypes susceptibles de se perpétuer dans les zones où seront multipliés les nouveaux cultivars. D'après Lawyer (1984), la sensibilité du pois à $M$ pinodes augmente avec la maturité physiologique. L'évaluation des cultivars doit donc être réalisée en tenant compte de la précocité de chacun.

La spécialisation géographique des pathotypes rend plus difficile l'amélioration pour la résistance à $A$ pisi (Wallen, 1957) et à $M$ pinodes (Ali et al, 1978). Est-il possible d'obtenir une résistance à large spectre vis-à-vis de $M p i$ nodes? Peut-on combiner davantage les résistances aux trois organismes pathogènes ? Un important travail de recherche paraît indispensable avant d'utiliser au mieux le matériel génétique nouvellement étudié. 
La récente application des techniques d'analyse du génome pourrait permettre dans un délai assez bref de caractériser avec précision le pouvoir pathogène et les gènes régissant la résistance de la plante hôte. Grâce au clonage de gènes suivi d'insertions localisées à des ADN d'origine végétale, il sera possible d'obtenir des plantes transgéniques porteuses des caractères de résistance, et permettant de franchir plus rapidement les limites inhérentes aux méthodes classiques utilisées pour l'amélioration des plantes (Lewis et Matthews, 1985).

\section{Lutte chimique}

\section{Traitement des semences}

Si les semences sont de bonne qualité, leur traitement permet d'inhiber pratiquement la transmission résiduelle (modalités 1 et 2 ) des agents d'anthracnose.

Maude et Kyle $(1970,1971)$ réussissent l'élimination d'A pisi grâce aux fongicides systémiques dérivés du benzimidazole (bénomyl, thiabendazole). En outre, ces mêmes substances réduisent de 19 à $1 \%$ l'incidence des nécroses substances réduisent de 19 à $1 \%$ l'incidence des nécroses du pied provoquées par $M$ pinodes (Maude et al, 1972). Champion et al (1984) confirment l'intérêt des benzimidazoles, y compris le carbendazime qui est la matière active la plus utilisée actuellement en France (Cailliez, 1990).

L'avenir de ces fongicides est toutefois remis en cause du fait du développement inquiétant de souches $\mathrm{d}^{\prime} A$ pisi et $M$ pinodes résistantes (Molinero et al, communication personnelle). Actuellement, des produits de remplacement d'efficacité comparable font encore défaut.

\section{Traitement des organes aériens}

Contre la dissémination secondaire, la généralisation de traitements, faisant appel aux benzimidazoles, a été accompagnée de l'apparition d'une résistance chez $A$ pisi et $M$ pinodes. Cette situation peut contraindre firmes et producteurs à des changements dans le choix des fongicides. Deux compositions ne faisant pas appel à ce groupe de fongicides sont proposées aujourd'hui. La première est à base de prochloraze et de mancozèbe. La seconde est constituée d'un mélange de flutriafol et de chlorothalonil. L'efficacité générale est satisfaisante (Daguenet et al, 1990). Le prochloraze et le flutriafol sont des inhibiteurs de la synthèse des stérols et sont dotés de propriétés curatives. Le mancozèbe et le chlorothalonil sont des fongicides multisites inhibant en particulier la respiration au niveau des mitochondries. Par l'inhibition de la germination des spores qu'ils provoquent, leur rôle apparaît totalement préventif.

La lutte chimique est devenue systématique. À des traitements de semences visant aussi Peronospora et pythiacées (fontes de semis), sont combinés des traitements en cours de végétation destinés à combattre Botrytis cinerea (pourriture grise). Cette lutte peut être envisagée pour les pois semés en automne souvent victimes d'une attaque précoce par le "complexe" des Ascochyta, comme pour les cultures irriguées par aspersion.

\section{Problèmes sanitaires généraux liés à la culture du pois}

Espérant compenser par des traitements fongicides polyvalents, le déficit de vigueur germinative et les risques d'attaque précoce des embryons par des champignons parasites (dont les trois espèces d'Ascochyta), certains producteurs de pois secs n'hésitent pas à diminuer les charges liées à l'achat de semences certifiées, en réservant une partie de leur récolte à fin de multiplication "semences fermières".

Par ailleurs, le pourcentage des surfaces irriguées par aspersion est jusqu'à présent en progression. Un excès durable d'humidité sous le couvert végétal est alors fréquemment observé. Cette situation annule le progrès consécutif à la généralisation des pois afila (ie à stipules surdéveloppés et sans folioles), qui devaient.constituer un milieu défavorable aux mycoses et permettre d'éviter certains traitements.

Enfin, l'installation de semi-saprophytes (Botrytis cinerea) ou de parasites classiques est favorisée, et le cultivateur peut être incité à pratiquer des traitements fongicides supplémentaires. La pression de sélection sur la population d'agents pathogènes s'en trouve accrue et une dérive de la résistance au carbendazime est enregistrée. II convient ici de rappeler la priorité à accorder aux mesures préventives découlant de la connaissance des particularités du cycle biologique de chacun de ces champignons. 


\section{REMERCIEMENTS}

Nous remercions vivement $\mathrm{R}$ Cousin, $\mathrm{P}$ Leroux, $\mathrm{G}$ Raynal et B Tivoli pour leurs suggestions et leurs conseils judicieux.

\section{RÉFÉRENCES}

Ali SM, Nitschke LF, Dube AJ, Krause MR, Cameron B (1978) Selection of pea lines for resistance to pathotypes of Ascochyta pinodes, Ascochyta pisi and Phoma medicaginis var pinodella. Aust J Agric Res $29,841-849$

Anselme C, Champion R (1962) L'analyse sanitaire des semences de pois. Proc Int Seed Testing Assoc 27, 3

Anselme C, Champion R (1971) La désinfection de semences de pois contaminées par Ascochyta pisi Lib, Ascochyta pinodes (Berk et Blox) Jones et Ascochyta pinodella Jones, agents de l'Anthracnose. Phytiatr Phytopharm 20, 13-21

Anselme C, Hewett PD, Champion R (1970) L'analyse sanitaire des semences de pois pour la recherche de l'Ascochyta pisi Lib. Méthodes d'analyse et limites de tolérance. $7 e$ Congr Int Protect Plantes

Bailey JA (1969) Phytoalexin production by leaves of Pisum sativum in relation to senescence. Ann Appl Biol 64, 315-324

Bateman DF (1976) Plant cell wall hydrolysis by pathogens. In: Biochemical aspects of plant parasite relationships (Friend $\mathrm{J}$, Threlfall $\mathrm{D}$, eds) Academic Press, New York, 79-103

Bateman DF, Basham HG (1976) Degradation of the plant cell walls and membranes by microbial enzymes. In: Encyclopedia of plant physiology. Physiological plant pathology, vol 4 (Heitefuss $\mathrm{A}$, Williams PH, eds) Springer-Verlag, Berlin, 316-355

Berkeley MJ (1841) Notices of British fungi (194). Ann Mag Nat Hist $\mathrm{f}-6,355-365$

Bertini S (1956) Su di un composto ad azione antibioca prodotto da Ascochyta pisi Lib. Ann Sper Agrar (Rome) NS, 11, 545-556

Biddle AJ (1983) The "Root rot complex" and its effect on vining Pea yield. PGRO The research station, Great North Road, Thornhaugh, Peterborough, GB

Bodker L (1989) The prevalence and importance of diseases in Denmark. J Dan State Seed Testing Stn 13-19

Boerema GH, Bollen GJ (1975) Conidiogenesis and conidial septation as differentiating criteria between Phoma and Ascochyta. Persoonia 8, 2, 111-144

Boerema GH, Dorenbosch MMJ, Leffring L (1965) A comparative study of the black stem fungi on lucerne and red clover and the footrot fungus on pea. Neth J Plant Pathol 71, 79-89

Bouznad Z (1989) Contribution à la connaissance du genre Ascochyta. Cas particulier de l'étude biologi- que ultra-structurale et cytochimique des relations hôte-parasite chez le couple Pisum sativum $\mathrm{L}-A s$ cochyta pisi Lib. Thèse de doctorat d'État, Université $P$ et $M$ Curie, Paris

Brewer D, MacNeill BH (1953) Preliminary studies in Ascochyta pisi Lib. Can J Bot 28, 645-672

Brewer JG, Boerema GH (1965) Electron microscope observations on the development of pycnidiospores in Phoma and Ascophyta spp. Proc Acad Sci Amst Ser C 68, 86-97

Buchanan PK (1987) A reappraisal of Ascochytula and Ascochytela (Coelomycetes). CAB IMI, Mycol Papers 156

Cailliez B (1990) Pois, les traitements de semences se corsent. Cultivar 287, 77-79

Carter MV, Moller WJ (1961) Factors affecting the survival and dissemination of Mycosphaerella pinodes (Berk and Blox) Vestergr in South Australian irrigated pea fields. Aust J Agric Res 12, 878-888

Champion $R$ (1978) Les maladies transmises par les semences. Perspect Agric (ITCF) 13, 42-46

Champion R, Bourdin J, Berthier J (1984) L'anthracnose du pois. Détermination des agents responsables et efficacité de divers fongicides en traitement de semences. Perspect Agric (ITCF) 77, 1419

Chup C, Sherf AF (1960) Vegetable diseases and their control. The Ronald Press Company, New York

Clulow SA, Lewis BG, Matthews P (1991a) A pathotype classification for Mycosphaerella pinodes. J Phytopathol 131, 322-332

Clulow SA, Lewis BG, Parker ML, Matthews P (1991b) Infection of pea epicotyles by Mycosphaerella pinodes. Mycol Res 95, 817-820

Collmer A, Keen NT (1986) The role of pectic enzymes in plant pathogenesis. Annu Rev Phytopathol 24, 383-409

Cousin R (1972) Contribution à l'étude des résistances à quelques maladies du pois. In: Eucarpia, Réunion Pois Versailles, INRA, Versailles, $149 p$

Cousin R, Messager A, Vingère A (1985) Breeding for yield in combining peas (improving disease resistance). In: The pea crop (Hebblethwaite PD, Heath MC, Dawkins TC, eds) Butterworth, London, 217128

Cruickshank IAM (1962) Studies on phytoalexins. IV. The antimicrobial spectrum of pisatin. Aust $J$ Biol Sci 15, 147-159

Cruickshank IAM, Perrin DR (1960) Isolation of a phytoalexin from Pisum sativum L. Nature 187, 799800

Cruickshank IAM, Perrin DR (1961) Studies on phytoalexins. III. The isolation, assay, and general properties of phytoalexin from Pisum sativum $L$. Aust $J$ Biol Sci 14, 336-348

Cruickshank IAM, Perrin DR (1963) Studies on phytoalexins. VI. Pisatin: the effect of some factors on 
its formation in Pisum sativum $L$ and the significance of pisatin in disease resistance. Aust $J$ Biol Sci 16, 111-128

Cruickshank IAM, Perrin DR (1965) Studies on phytoalexins. VIII. The effect of some further factors on formation, stability and localization of pisatin in vivo. IX. Pisatin formation by cultivars of Pisum sativum $L$ and several other Pisum species. Aust $J$ Biol Sci 18, 803-835

Daguenet G, Clinkspoor H, Remuaux M (1990) Les traitements fongicides en végétation sur pois. Perspect Agric (ITCF) 153, 43-44

Darby $P$, Lewis BG, Matthews P (1985) Inheritance and expression of resistance to Ascochyta pisi. In: The pea crop (Hebblethwaite PD, Heath MC, Dawkins TCK, eds) Butterworths, London, 231-236

Darby $P$, Lewis BG, Matthews P (1986) Diversity of virulence within Ascochyta pisi and resistance in the genus Pisum. Plant Pathol 35, 214-223

Davis DW, Shehata MA (1985) Breeding for resistance to root-rot pathogens of peas. In: The pea crop (Hebblethwaite PD, Heath MC, Dawkins TC, eds) Butterworths, London, 237-245

Dekker J (1957) Internal seed desinfection of peas infected by Ascochyta pisi by means of the antibiotics rimocidin and pimaricin, and some aspects of the parasitism of this fungus (Neerl). Tijdschr Plantenziekten 63, 65-144

Deverall BJ, Wood RKS (1961) Chocolate spot of beans (Vicia faba $L$ ) interactions between phenolase of host and pectic enzymes of the pathogen. Ann Appl Biol 49, 473-487

Dickinson GH, Sheridan JJ (1968) Studies on the survival of Mycosphaerella pinodes and Ascochyta pisi. Ann Appl Biol 62, 473-483

Didelot D, Allard C, Bill L, Maumene C (1992) Pourriture racinaire du pois protéagineux. Identification en France du complexe parasitaire. Troisième Conférence Internationale sur les maladies des plantes. Bordeaux, 3-5 décembre 1991, ANPP, 579-586

Dixon GR (1988) Mycosphaerella pinodes (Berk et Bloxam) Vestergren; Ascochyta pisi Lib; Phoma medicaginis Malbr et Roum Var pinodella (LK Jones) Boerema. In: European handbook of plant diseases (Smith IM, Dunez J, Phillips DH, Lelliott RA, Archer SA, eds) Blackwell Sci Publication, Oxford, 351, 352, 398

Dixon RA, Lamb CJ (1990) Molecular communication in interactions between plants and microbial pathogens. Ann Rev Plant Physiol 41, 339-367

Dorenbosch MMJ (1970) Key to nine ubiquitous soilborne Phoma-like fungi. Persoonia 6, 1, 1-14

Gilchrist GC (1926) The nature of resistance to foot rot caused by Ascochyta sp and some other fungi in the epicotyl of the pea. Phytopathology 16, 269-276

Gilpatrick JD, Busch LV (1950) Studies on the pathogenicity of different isolates of Ascochyta pisi Lib. Plant Dis Reptr 34, 383-387
Gould CJ (1949) Ascochyta pinodella footrot of peas in western Washington. Phytopathology 39, 947949

Gregory PH, Guthrie EJ, Bunce ME (1959) Experiments on splash dispersal of fungis spores. $J$ Gen Microbiol 20, 2, 328-354

Hadwiger LA, Beckman JM, Adams MJ (1981) Localization of fungal components in the pea-Fusarium interaction detected immunochemically with antichitosan and anti-fungal cell wall antisera. Plant Physiol 67, 170-175

Hagedorn DJ (1985) Diseases of peas: their importance and opportunities for breeding for disease resistance. In: The pea crop (Hebblethwaite PD, Heath MC, Dawkins TCK, eds) Butterworths, London, 205-213

Hare WW, Walker JC (1944) Ascochyta diseases of canning pea. Wis Agric Exp Stn Res Bull 150, 1-31

Heath MC (1981) A generalized concept of hostparasite specificity. Phytopathology 71, 1121-1123

Heath MC, Wood RKS (1969) Leaf spots induced by Ascochyta pisi and Mycosphaerella pinodes. Ann Bot NS 33, 657-670

Heath MC, Wood RKS (1971a) Role of cell wall degrading enzymes in the development of leaf spots caused by Ascochyta pisi and Mycosphaerella pinodes. Ann Bot NS 35, 451-474

Heath MC, Wood RKS (1971b) Role of inhibitors of fungal growth in the limitation of leaf spots caused by Ascochyta pisi and Mycosphaerella pinodes. Ann Bot NS 35, 475-491

Hickman CJ (1941) The prevalance and significance of pea-seed infection by Ascochyta sp. Long Ashton Agric Hortic Res Stn, Annu Rep 1940, 50-54

Hubbeling N (1972) Races of Ascochyta pisi and testing for resistance in peas. In: Eucarpia Réunion Pois Versailles. INRA, Versailles, 161-162

Ingham JL (1982) Phytoalexins from the Leguminosae. In: Phytoalexins (Bailey JA, Mansfield JW, eds) Blackie \& Son Ltd, Glasgow, 49

Iwai I, Mishima M (1965) Constitution of aschochitine. Chem Indust 186-187

Jones FR, Linford MB (1925) Pea disease survey in Wisconsin. Wis Agric Exp Stn Res Bull 64

Jones LK (1927a) The relation of Mycosphaerella pinodes to Ascochyta blight of peas. Phytopathology (abstract) 17, 44

Jones LK (1927b) Studies of the nature and control of blight, leaf and pod spot and footrot of peas caused by species of Ascochyta. NY State Agric Exp Stn Bull 547, 1-45

Keen NT (1982) Specific recognition in gene-forgene host-parasite systems. Adv Plant Pathol 1, 35-82

Keen NT, Legrand M (1980) Surface glycoproteins: evidence that they may function as the race specific phytoalexin elicitors of Phytophtora megasperma $f$ sp glycinea. Physiol Plant Pathol 17, 175-192 
Keen NT, Yoshikawa M, Wang MC (1983) Phytoalexin elicitor activity of carbohydrates from Phytophtora megasperma f sp glycinea and other sources. Plant Physiol 71, 466-471

Kerling LCP (1949) Attack of peas by Mycosphaerella pinodes (Berk and Blox) Stone (Neerl). Tijdschr Plantenziekten 55, 41-68

Kuc J, Williams EB, Maconkin MA, Ginzel J, Ross AF, Freedman LJ (1967) Factors in the resistance of apple to Botryosphaeria ribis. Phytopathology 57, 38-42

Land (Van'T) BG, Wiersma-Van Duin ED, Fuchs A (1975a) In vitro and in vivo conversion of pisatin by Ascochyta pisi. Acta Bot Neerl 24, 251

Land (Van'T) BG, Wiersma-Van Duin ED, Fuchs A (1975b) The possible role of ascochitine in the combination Ascochyta pisi-pea. Acta Bot Neerl 24, 252

Lawyer AS (1984) Diseases caused by Ascochyta spp. In: Compendium of pea diseases (Hagedorn DJ, ed) Soc Phytopathol, États-Unis, 11-15

Lepoivre P (1981) Effet de l'ascochitine sur les protoplastes de Pisum sativum L. Bull Rech Agron Gembloux 16, 27-34

Lepoivre $P$ (1982a) Sensitivity of pea cultivars to ascochitine and the possible role of the toxin in the pathogenicity of Ascochyta pisi Lib. Phytopathol Z 103, 25-34

Lepoivre $\mathrm{P}(1982 \mathrm{~b})$ Extraction d'ascochitine à partir de feuilles de pois infecées par Ascochyta pisi Lib ou Mycosphaerella pinodes (Berk and Blox). Vestergr Parasitica 38, 2, 45-53

Lewis BG, Matthews P (1985) The world germplasm of Pisum sativum: could it be used more effectively to produce healthy crops? In: The pea crop (Hebblethwaite PD, Heath MC, Dawkins TCK, eds) Butterworths, London, 215-229

Linford MB, Sprague R (1927) Species of Ascochyta parasitic on the pea. Phytopathology 17, 381-398

Lyall LH (1949) Peas. Breeding and selection for resistance to Ascochyta blight. Progress Rept 19341948; 69-70. Hort Div Central Exptl Farm Can Dept Agr, Ottawa

Lyall LH, Wallen VR (1958) The inheritance of resistance to Ascochyta pisi Lib in peas. Can J Plant Sci $38,215-218$

Madhosingh C, Wallen VR (1968) Serological differentiation of the Ascochyta species on peas. Can J Microbiol 14, 449-451

Maude RB (1966) Pea seed infection by Mycosphaerella pinodes and Ascochyta pisi and its control by seed soaks in thiram and captan suspensions. Ann App/ Biol 57, 193-200

Maude RB, Kyle AM (1970) Seed treatments with benomyl and other fungicides for the control of Ascochyta pisi on peas. Ann Appl Biol 66, 37-41

Maude RB, Kyle AM (1971) Seed dressings with systemic fungicides for the control of seed-borne fungal pathogens. 21st Annual Report (1970). National Ve- getable Research Station, Wellesbourne, Warwick, 106

Maude RB, Kyle AM, Moule CG, Dudley C (1972) Seed dressings with systemic fungicides for the control of seed-borne fungal pathogens. 22th Annual Report (1971). National Vegetable Research Station, Wellesbourne, Warwick, 75

Neergaard P (1979) Seed pathology. Macmillan Press Ltd, London, 2 vol, 1191

Nevins DJ, English PD, Albersheim P (1968) Changes in cell wall polysaccharides associates with growth. Plant Physiol (Lancaster) 43, 914-922

Noll W (1939) Untersuchungen über Fuss- und Welkenkrankheiten bei Leguminosen. Z Pflanzenkr 49, 6, 385-431

Noll W (1940) Uber weitere Befallsymptome und Massnahmen zur Verhütung von Schäden durch Ascochyta pinodella Jones, Ascochyta pisi Lib und Mycosphaerella pinodes (Berk und Blox) Stone bei Erbsen. Z Pflanzenkr 50, 7, 49-71

Oku H, Nakanishi T (1963) A toxic metabolite from Ascochyta fabae having antibiotic activity. Phytopathology 53, 1321-1325

Oku H, Shiraishi T, Ouchi S, Ishiura M, Matsueda R (1980) A new determinant of pathogenicity in plant disease. Naturwissenschaften 67, S 310

Ondrej M (1973) The results of the study of the occurrence of the biotypes (races) of the fungus Mycosphaerella pinodes (Berk and Blox) Stone. Ochr Rost 9, 49-56

Paxton JD (1981) Phytoalexins. A working redefinition. Phytopathol Z 101, 106-109

Petrak F (1924) Mykologische Notizen. VII (Mycological Notes VII). Ann Mycol 1-2, 16-18

Pierre RE, Millar RL (1965) Histology of pathogen suspect relationship of Stemphylium botryosum and alfalfa. Phytopathology 55, 909-914

Platero Sanz M, Fuchs A (1980) Short-lived protection of pea plants against Mycosphaerella pinodes by prior inoculation with Pseudomonas phaseolicola. Neth J Plant Pathol 86, 181-190

Punithalingam E (1979) Graminicolus Ascochyta species. CAB CMI Mycol Papers 142, 214

Punithalingam E, Gibson IAS (1976) Phoma medicaginis var pinodella. In: Descriptions of pathogenic fungi and bacteria CMI Kew, Surrey, 518

Punithalingam E, Holliday P (1972) Ascochyta pisi, Mycosphaerella pinodes. In: Descriptions of pathogenic fungi and bacteria. CMI Kew, Surrey, 334-340

Rabenhorst L (1884) Kryptogamen-Flora von Deutschland Oesterreich und der Schweisz: Pilze, vol 2 (Winter $G$, ed). Verlag von $E$ Kummer ( $2^{e}$ edition) Leipzig, 377

Rouxel T (1989) Les phytoalexines et leur intervention dans la résistance hypersensible aux champignons phytopathogènes. Agronomie 9, 529-545

Saccardo PA (1884) Sphaeropsidearum et Melanconiearum. Syll Fung 3, 397-398 
Sattar A (1933) A comparative study of the fungi associated with blight diseases of certain cultivated leguminous plants. Trans Br Mycol Soc 18, 276-301

Sheridan JJ (1973) The survival of Mycosphaerella pinodes on pea haulm buried in soil. Ann Appl Biol $75,196-203$

Shiraishi T, Oku H, Tsuji Y, Ouchi S (1978a) Inhibitory effect of pisatin on infection process of Mycosphaerella pinodes on pea. Ann Phytopathol Soc Jpn 44, 641-645

Shiraishi T, Oku H, Yamashita M, Ouchi S (1978b) Elicitor and suppressor of pisatin induction in spore germination fluid of pea pathogen, Mycosphaerella pinodes. Ann Phytopathol Soc Jpn 44, 659-665

Skolko AJ, Groves JW, Wallen VR (1954) Ascochyta diseases of peas in Canada with special reference to seed transmission. Can J Agric Sci 34, 417-428

Sprague R (1929) Host range and life-history study studies of some leguminous Ascochytae. Phytopathology 19, 917-932

Stone RE (1912) The life history studies of Ascochyta on some leguminous plants. Ann Mycol 10, 564592

Tivoli B, Lemarchand E (1992) Fungal and bacterial foliar disease survey of combining pea in France in 1991. $1^{\text {re }}$ conférence européenne protéagineux, Angers, 363-364

VanEtten HD, Matthews DE, Matthews PS (1989) Phytoalexin detoxification: importance for pathogenicity and practical implications. Annu Rev Phytopathol 27, 143-164

Viennot-Bourgin $\mathrm{G}$ (1949) Les champignons parasites des plantes cultivées. Masson et C, Paris, 1851, 458

Walker JC (1952) Aschochyta diseases. In: Diseases of vegetable crops (1st edition). Mac Graw-Hill Book Company Inc, New-York, 529 p

Wallen VR (1955) The effect of storage for several years on the viability of Ascochyta pisi in pea seed and on the germination of seed and emergence. Plant Dis Rep 39, 674-677
Wallen VR (1957) The identification and distribution of physiologic races of Ascochyta pisi Lib in Canada. Can J Plant Sci 37, 337-341

Wallen VR (1965) Field evaluation and the importance of the Ascochyta complex on peas. Can J Plant Sci $45,27-33$

Wallen VR (1974) Influence of three Ascochyta diseases of peas on plant development and yield. Can Plant Dis Survey 54, 3, 86-90

Wallen VR, Cuddy TF (1968) Ascochyta blight of field peas. Can Agric 13, 24-25

Wallen VR, Cuddy TF, Grainger PN (1967) Epidemiology and control of Ascochyta pinodes on field peas in Canada. Can J Plant Sci 47, 395-403

Wallen VR, Jeun $J(1968)$ Factors limiting the survival of Ascochyta spp of peas in soil. Can J Bot 45, 10, 1279-1286

Wallen VR, Wong SI, Jeun J (1967) Isolation, incidence and virulence of Ascochyta spp of peas from the soil. Can J Bot 45, 12, 2243-2247

Wehlburg $C$ (1932) Onderzoekingen over enwtenanthracnose. Thèse Université Utrecht (Baarn), $65 \mathrm{p}$

Weimer JL (1947) Resistance of Lathyrus spp and Pisum spp to Ascochyta pinodella and Mycosphaerella pinodes. J Agric Res $75,181-190$

Wit (de) PJGM (1986) Elicitation of active resistance mechanisms. In: Biology and molecular biology of plant pathogen interactions (Bailey J, ed) SpringerVerlag, Berlin, 149-169

Yamada T, Hashimoto H, Shiraishi T, Oku H (1989) Suppression of pisatin, phenylalanine ammonialyase mRNA, and chalcone synthase mRNA accumulation by a putative pathogenicity factor from the fungus Mycosphaerella pinodes. Mol Plant-Microbe Interact 2, 256-261

Yamamoto Y, Oku H, Shiraishi T, Ouchi S, Koshizawa K (1986) Non-specific inducation of pisatin and local resistance in pea leaves by elicitors from $M y$ cosphaerella pinodes, $M$ melonis and $M$ Ligulicola and the effect of suppressor from $M$ pinodes. J Phytopathol 117, 136-143 